\title{
Correction to: Ventricular Cryoinjury as a Model to Study Heart Regeneration in Zebrafish
}

\author{
Ines J. Marques, Andrés Sanz-Morejón, and Nadia Mercader
}

\section{Correction to:}

Chapter 5 in: Kenneth D. Poss and Bernhard Kühn (eds.), Cardiac Regeneration: Methods and Protocols, Methods in Molecular Biology, vol. 2158, https://doi.org/10.1007/978-1-0716-0668-1_5

Chapter 5 of this book was originally published non-open access. The chapter has now been converted to open access chapter under a CC BY 4.0 license and the Copyright Holder is "The Author(s)". The book has also been updated with this change. 